\title{
Gravetiense y Solutrense en la Península Ibérica
}

\author{
Sergio Ripoll López \\ Eduardo Ripoll Perello*
}

Varios han sido los intentos de sintetizar el Gravetiense o Perigordiense, desde que durante el $X$ Congreso de la U.I.S.P.P. se estableciera la Comisión 10. Ésta ya ha efectuado varias reuniones con el fin de clarificar y unificar las ideas que se tienen sobre este periodo.

La oportación española sobre Gravetiense ha sido bastante escasa centrándose en los trabajos de F. Bernaldo de Quirós (1977, 1981 y 1982) e I. Barandiarán (1980) para la cornisa cantábrica, y los de C. Cacho (1981), J. M. Fullola (1979) y N. Soler (1986) para el área mediterránea.

En primer lugar nos ocuparemos del Norte de la Península Ibérica y posteriormente de la zona levantina. Las diferencias entre las dos zonas expuestas están claramente marcadas, ya que si bien en la zona levantina hay un dominio de la "tradición gravetiense", en el área cantábrica se mantiene una "tradición auriñaciense" aunque introduciendo algunos elementos gravetienses, dentro de los límites que supone hablar de elementos "auriñacienses" y "gravetienses".

El Gravetiense en el Norte peninsular habría que situarlo cronológicamente entre el $20.710 \pm 340 \mathrm{~B}$. P. (SI-953) del nivel Va atribuido al Perigordiense Superior de cueva Morín (González Echegaray, J., y Freeman, L. G., 1971) y el $20.360 \pm 450$ B. P. (Ly-1783) del nivel Presolutrense ("Auriñaciense") de la cueva de La Riera (Strauss, L. G., et alii,

Departamento de Prehistoria e Historia Antigua de la Universidad Nacional de Educación a Distancia, calle Senda del Rey, s/n., 28040 Madrid, España. 


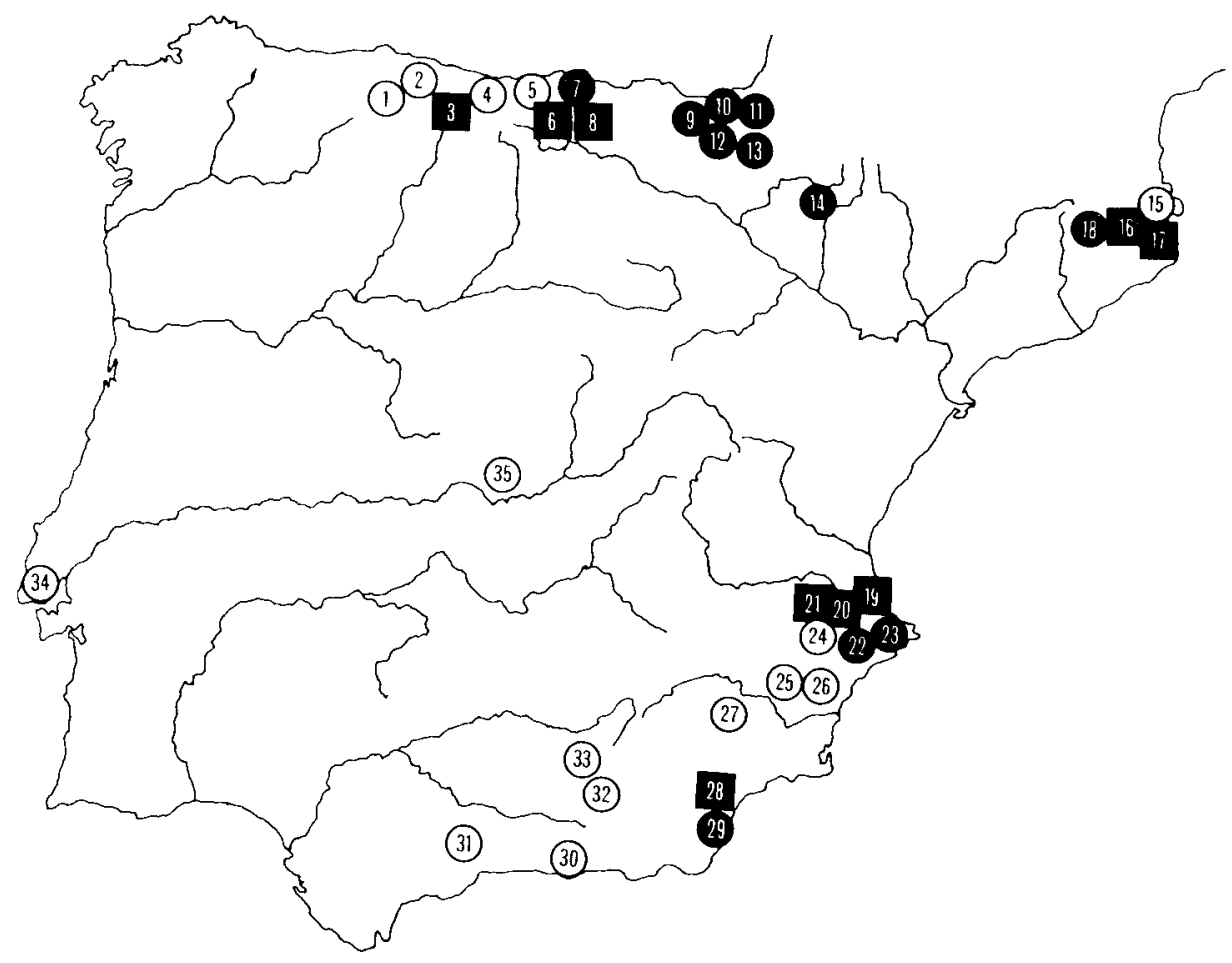

Fig. 1. Repartición de los yacimientos relacionados en el texto con industrias gravetienses y solutrenses. 1. Cueva de Cueto de la Mina. 2. Cueva de Las Caldas. 3. Cueva de La Riera. 4. Cueva Chufín. 5. Cueva de Altamira. 6. Cueva de El Castillo. 7. Cueva del Pendo. 8. Cueva Morín. 9. Le Basté. 10. Cueva de Gatzarria. 11. Cueva de Isturitz. 12. Cueva de Lezetziki. 13. Cueva de Bolinkoba. 14. Cueva de Chaves. 15. Cueva del Cau de Les Goges. 16. Cueva del Reclau Viver. 17. Cueva de L'Arbreda. 18. Cueva del Roc de la Melca. 19. Cueva de Les Mallaetes. 20. Cueva del Parpalló. 21. Cueva de Barranc Blanc. 22. Cueva de Les Maravelles. 23. Cueva de Els Porcs. 24. Cueva Beneito. 25. Cueva de Ios Mortolitos. 26. Cueva de Cejo del Pantano. 27. Cueva de Ambrosio. 28. Cueva del Serrón. 29. Cueva de Zajara II. 30. Cueva de Nerja. 31. Cueva del Tajo del Jorox. 32. Cueva del Pantano de Cubillas. 33. Cueva de los Ojos. 34. Yacimientos del área de Madrid. 35. Yacimientos portugueses.

- Yacimientos gravetienses.

- Yacimientos gravetienses y solutrenses.

Yacimientos solutrenses. 
1986; Bernaldo de Quirós, F., 1982), ya que la reciente datación de $19.390 \pm 380$ B. P. (I-6144) del nivel Illa de Lezetziki resulta demasiado reciente para atribuirla a un Auriñaciense Superior $O$ auriñaco-perigordiense (Barandiarán, I., 1980).

Son los análisis palinológico y paleontológico del yacimiento de isturitz (Leroi-Gourhan, Arl., 1959) y la sedimentología de las estaciones de Lezetziki, Gatzarria, El Pendo (Butzer, K. W., 1980) y La Riera (Laville, $H ., 1980$ ) los que permiten situar el Gravetiense, dentro de un momento frio y húmedo del Würm III (Pleniglaciar superior), con un paisaje en el que domina la estepa, y una ausencia casi total de especies arbóreas y una fauna de tipo frio. Sin embargo, en la revisión realizada por $\mathrm{M}$. Hoyos y H. Laville (1982) de la cueva santanderina de El Pendo se cuestiona la secuencia cronoestratigráfica establecida por los excavadores, aduciendo una posible contaminación de los niveles gravetienses.

A diferencia de lo que ocurre en el Auriñaciense, el Gravetiense o Perigordiense no se encuentra bien representado en la cornisa cantábrica. Este momento cultural plantea una serie de interesantes cuestiones como es la pervivencia de elementos auriñacienses junto con útiles muy característicos del Gravetiense. Según F. Bernaldo de Quirós (1982) "existiria una "aculturación" no teniendo el Perigordiense $V$ la suficiente fuerza para variar estos conjuntos, por otra parte, muy bien adaptados, del Auriñaciense Evolucionado Cantábrico". Dentro de este momento podemos distinguir dos grupos, uno con buriles de Noailles y el otro con puntas pedunculadas del tipo Font Robert. Dentro del primero podemos situar los yacimientos de Isturitz, Bolinkoba (País Vasco) y la cueva del Castillo (Cantabria) en los que al tipo ya mencionado se le asocian puntas de La Gravette de muy buena factura. El segundo grupo estaría representado en cueva Morin (Cantabria), donde las puntas de La Gravette aparecen asociadas a puntas de la Font Robert (Bernaldo de Quirós, F., 1982). También se han hallado este tipo de industrias en otros yacimientos del área cantábrica, pero su encuadre en uno de estos dos grupos no es tan claro como veremos a continuación.

Es en el yacimiento de Isturitz donde las características industriales permiten definir claramente el Perigordiense Superior o $V_{c}$ con buriles de Noailles. Según los estudios de R. y S. de Saint Perier (1952) sobre un total de más de 11.000 útiles se observa un significativo incremento del grupo de los buriles que alcanza un $46,8 \%$. La existencia de un alto indice de puntas de La Gravette $(3,4 \%)$, junto con las características azagayas con una extremidad estriada («puntas de Isturitz»), permite encuadrar de una forma definitiva este horizonte cultural. En este mismo momento podemos situar el yacimiento de Bolinkoba gracias al hallazgo 
de dos azagayas o "puntas de Isturitz" en el nivel F o VI. La principal característica de esta estación es su especialización en la caza de la cabra montés.

El Perigordiense Final esta perfectamente localizado en el nivel III de la cueva de Isturitz y en la cueva de Gatzarria (nivel cbcs). Industrialmente este momento se caracteriza principalmente por el brusco empobrecimiento de los tipos que encontrábamos en el período anterior. En el yacimiento al aire libre de Le Basté el análisis palinológico muestra un aumento del índice arbóreo, con unas condiciones climáticas más benignas que podrían corresponder a un momento final del Perigordiense (Barandiarán, I., 1980).

En Cantabria, el Perigordiense se encuentra localizado, como ya hemos mencionado antes, en cueva Morín (niveles $V$ y IV), en la cueva del Castillo (niveles 12 y 14), en la cueva del Pendo (niveles $V a$ y $V$ ) y en La Riera (nivel 1). En el nivel $V$ superior de cueva Morín, atribuido al Perigordiense, encontramos una serie industrial compuesta, entre otros, por buriles, que únicamente alcanzan un $11,6 \%$. La confirmación de que no se trata de un nivel auriñaciense es el alto porcentaje $(28,7 \%)$ que alcanzan las puntas de La Gravette y otras piezas que componen el llamado "grupo perigordiense». Según J. González Echegaray y L. G. Freeman (1971) este nivel habría que encuadrarlo dentro de un Perigordiense IV dada la ausencia de buriles de Noailles o piezas con truncatura, frente a las numerosas puntas de La Gravette.

En la cueva del Castillo, el nivel 14 se puede encuadrar en el Perigordiense $\mathrm{V}$, con características comunes con el Perigordiense Superior de la región cantábrica (Bernaldo de Quirós, F., 1982). El índice de raspadores $(32,78 \%)$ es superior al de los buriles $(25,4 \%)$, mientras que los integrantes del grupo perigordiense alcanza un $11,47 \%$. La presencia de buriles de Noailles y dos puntas de La Gravette permite atribuir este nivel al Gravetiense. El nivel 12 es ligeramente diferente, ya que los buriles $(15,67 \%)$ dominan frente a los raspadores $(12,68 \%)$. El grupo perigordiense $(6,71 \%)$ está compuesto por «1 golpe de buril de borde abatido total, otro parcial y siete hojas de truncatura retocada" (Cabrera, V., 1984). Además se cita la existencia de una punta de la Font Robert en las colecciones de $\mathrm{H}$. Obermaier. Este nivel es situado por V. Cabrera (1984) en un Perigordiense Superior sensu lato.

El yacimiento del Pendo ha proporcionado en el nivel $V a$ una serie industrial bastante pobre, en la que el grupo perigordiense $(9,9 \%)$ está presente con "algunas hojitas de dorso rebajado, una de las cuales po- 
dría ser considerada como una microgravette». Pese a contener algunos elementos auriñacienses, dadas las características expuestas hay que pensar que este nivel puede atribuirse a un Perigordiense Superior o Gravetiense (González-Echegaray, J., et alli, 1980). El nivel V continúa teniendo un escaso conjunto de útiles, pero la existencia de una punta de la Font Robert, así como algunas hojitas que componen el grupo perigordiense que alcanza un $37,5 \%$, permite encuadrar asimismo este nivel en un Periogordiense Superior o Gravetiense.

El encuadre cultural del nivel 1 de La Riera en el Gravetiense no es fácil a pesar de que tanto los raspadores como los buriles aparecen con el mismo porcentaje $(15,8 \%)$, mientras que las hojitas de dorso sólo representan un 1,8\%. Para este nivel encuadrado en un Presolutrense se cuenta con una datación radiocarbónica de $20.360 \pm 450$ B. P. (Strauss, L. G., et alii, 1986; Bernaldo de Quirós, F., 1980).

En el área mediterránea, como ya hemos expuesto antes, el Gravetiense se presenta con unas características diferentes a las del área cantábrica. Las dataciones radiocarbónicas permiten situar este período aquí entre el $29.690 \pm 560$ B. P. (KN-1920) del nivel aurinaciense evolucionado de la cueva de Les Mallaetes (Fortea, J., y Jordá, F., 1976) y el $20.490 \pm 900 / 800$ B. P. (BM 859) del nivel Solutrense Inferior de la cueva del Parpalló (Davidson, I., 1974). Para el nivel del Perigordiense Superior del yacimiento del Reclau Viver contamos con unas dataciones de $14.800 \pm 600$ B. P. $(M-1018)$ y $14.750 \pm 600$ B. P. (M-1017), que parecen estar contaminadas, ya que no se relacionan en absoluto con la clasificación de las industrias (Soler, N., 1986).

Climáticamente el Gravetiense se define gracias a la sedimentología de Les Mallaetes que muestra unas condiciones relativamente frias y húmedas con frecuentes ciclos de hielo y deshielo. Esta misma situación se refleja en el análisis polínico que presenta una alternancia de un paisaje de bosque a otra de estepa, pero con una permanencia de especies que todavía hoy podemos encontrar. La fauna está representada, como casi a lo largo de toda la secuencia, por Cervus elaphus, Capra pyrenaica y Oryctolagus cuniculus (Fortea, J., et alii, 1983).

En Cataluña contamos con los yacimientos de Reclau Viver (niveles C y D) y L'Arbreda (niveles 17 a 24) en los que la serie industrial está dominada por el grupo de los raspadores y buriles junto con piezas de dorso asociadas a una industria ósea compuesta por azagayas de base hendida. Para N. Soler (1986) los yacimientos de Serinyá son muy tardios, casi presolutrenses. Este horizonte cultural se ha encontrado también en el Roc de la Melca para el que se posee una datación de 
$20.900 \pm 400$ B. P., que es ligeramente anterior al Gravetiense Superior de L'Arbreda (Soler, N., 1986)

El Gravetiense en el País Valenciano no se caracteriza por un amplio dominio de los raspadores sobre cualquier otro grupo tipológico (Miralles, J. L., 1982). Los dos yacimientos más importantes son El Parpalló $(8,50-$ $7,25)$ metros) y Les Mallaetes (niveles $\mathrm{VI}$ a XI). En la primera estación, como ya hemos visto, los raspadores $(64 \%)$ dominan frente a los buriles que apenas alcanzan un $8 \%$ y están asociados a un importante grupo de piezas de dorso (15\%) (Pericot, L., 1942; Fullola Pericot, J. M., 1979). Algo parecido ocurre en Les Mallaetes donde los raspadores poseen un indice de $34,7 \%$, los buriles un $7,8 \%$ mientras que las piezas con retoque continuo alcanzan un $25,3 \%$ (Fortea, J., y Jordá, F, 1976). También se ha citado este momento cultural en Barranc Blanc en el que la composición industrial es muy parecida, aumentanto los buriles $(12,83 \%)$ y existiendo sólo microgravettes (Fullola Pericot, J. M., 1979, y Miralles, J. L., 1982). Otros yacimientos de menor importancia son Les Maravelles (Villaverde, V., 1979) y Els Porcs (Aparicio, J., 1977).

En Andalucía los datos son más escasos no existiendo ninguna datación ni tampoco referencias cronoestratigráficas. Las industrias proceden de excavaciones antiguas realizadas por L. Siret a principios de siglo y revisadas por C. Cacho (1981). Estos yacimientos son Zajara II y el Serrón cuyas industrias muy características del Gravetiense en el caso de la primera estación, son similares a las descritas en el País Valenciano.

Pocas atribuciones pueden hacerse al arte gravetiense en la Peninsula lbérica. Acaso pertenecen a él algunos de los conjuntos de grabados en bocas de pequeñas cuevas del valle del río Nalón (Asturias) estudiadas por J. Fortea pero que todavía no han sido publicados en detalle.

Sólo con argumentos estilísticos pueden atribuirse al Gravetiense los hallazgos de tipo paleolítico realizados por $\mathrm{V}$. Baldellou en la zona prepirenaica de la provincia de Huesca. En la cueva del Forcón hay un pequeño friso de "macarroni» y en la Fuente del Trucho tres protomos y dos figuras completas de caballo, junto con manos con dedos mutilados o replegados (Baldellou, V., 1987).

Al igual que para el Gravetiense en el Solutrense también existen dos zonas que se situarían al ambos lados de un teórico eje que iría desde Lisboa a Gerona pasando por Madrid.

Las principales razones para esbozar las diferencias existentes entre ambas áreas son principalmente tipológicas y se manifiestan con mayor 
profusión en los momentos finales del Solutrense. Las características principales son la existencia o no de retoque plano sobre las puntas de muesca, así como la presencia o no de puntas de aletas y pedúnculo en el Solutrense Superior Evolucionado.

En la cornisa cantábrica numerosos han sido los yacimientos en los que se ha identificado este periodo que podemos encuadrar entre el $20.360 \pm 450$ B. P. (Ly-1783) del nivel Presolutrense, y el $15.690 \pm 310$ B. P. del nivel Solutrense Superior de La Riera (Strauss, L. G., 1983; Strauss, L. G., y Clark, G., 1986). La condiciones climáticas eran frias y secas con algunas oscilaciones más templadas y húmedas. El paisaje estaba compuesto por praderas/estepas, con pinos y especies termófilas durante los episodios más templados. La fauna, de carácter pleniglaciar, estaba representada por caballo, bisonte, ciervo y cabra, aunque hay que destacar la escasa presencia de reno.

La descripción de los principales yacimientos en los que se han identificado industrias solutrenses se hace empezando por Asturias para a continuación pasar a Santander.

En el yacimiento de Cueto de la Mina, el Conde de la Vega del Sella, en 1916, identificó una serie de niveles que abarcan desde el Auriñaciente hasta el Asturiense (Vega del Sella, 1916). El horizonte solutrense fue hallado en los niveles $F$ y $E$. La serie industrial del nivel $F$ está compuesta por cinco puntas de cara plana, nueve hojas de laurel, una hoja de sauce y tres puntas de muesca de retoque plano. Este grupo de útiles en el nivel $E$ está representado por nueve puntas de cara plana, 16 hojas de laurel, 1 hoja de sauce y 21 puntas de muesca. Para F. Jordá (1955) el primer nivel seria un estrato de transición, mientras que el nivel superior se encuadraría en un Solutrense clásico o Solutrense Superior.

Las excavaciones realizadas por L. G. Strauss en la cueva de La Riera ha permitido descubrir 17 niveles solutrenses que pertenecerian a un solo momento atribuible al Solutrense Superior (Strauss, L. G., 1983). Para este yacimiento se cuenta con una serie de dataciones que oscilan desde un $20.970 \pm 620$ B. P. (GrK-6984) del nivel 4 hasta un $15.690 \pm 310$ B. P. (UCR 1271 A) del nivel 14. Podría tratarse de un mismo momento cultural, encuadrable en el Solutrense Superior dada la existencia de puntas de muesca junto con hojas de laurel y la ausencia de puntas de cara plana.

El yacimiento de Las Caldas, situado en la cuenca del Nalón, posee una estratigrafía que abarca desde el Solutrense Medio hasta el Magdaleniense Medio. El primer momento ocupacional, dividido en dos partes, 
el grupo solutrense de la fase más antigua (A) aparece con un índice de $11,22 \%$, mientras que en la fase $B$ los útiles foliáceos alcanzan un $14 \%$. El paso del Solutrense Medio al Superior es gradual y lento. Siguen apareciendo piezas solutrenses bifaciales, mientras que hace su aparición la hoja de laurel de base cóncava y la punta de muesca unifacial con retoque plano. El conjunto que abarca desdel el nivel 6 hasta el final de la secuencia solutrense se puede encuadrar en el "Solutrense Terminal» (Corchón, M. S., 1981).

En las Caldas se observa una evolución industrial entre los diferentes niveles. El Solutrense Medio, según M. S. Corchón (1981), es bastante similar en su estructura y tipo al Solutrense Medio del Suroeste francés, mientras que el Solutrense Superior muestra unos rasgos característicos que le son propios.

Chufín es el último yacimiento descubierto en la zona y en el que se encontró un nivel solutrense. Este único estrato proporcionó un conjunto representado por puntas de cara plana $(8,82 \%)$, hojas de laurel $(7,02 \%)$, hojas de sauce $(0,73 \%)$ y puntas de muesca $(2,20 \%)$ de base cóncava. Para este nivel se cuenta con una datación radiocarbónica de $17.420 \pm 200$ B. P. (C.S.I.C.), que permite incluirlo dentro de un Solutrense Superior (Cabrera, V., 1977).

La cueva de Altamira, a pesar de no ser un yacimiento solutrense importante, creemos que debe ser tratada aqui por el interés de sus representaciones parietales. La primera excavación sistemática, llevada a cabo por H. Alcalde del Río en 1904 (1906), permitió identificar dos niveles de los que el inferior fue atribuido al Solutrense con puntas de muesca (Breuil, H., y Obermaier, H., 1935). F. Jordá (1955) encuadra este nivel en un momento final del Solutrense cantábrico. Mientras que L. G. Strauss (1983), criticando los estudios anteriores duramente, no aporta ningún dato sobre el momento cultural concreto al que se puede atribuir esta industria.

El yacimiento de la cueva del Castillo cuenta con la secuencia más larga de Europa, ya que abarca desde el Achelense hasta el Bronce. El nivel solutrense situado entre el nivel subyacente -Perigordiense Superior- y el superior - Magdaleniense Inferior- proporcionó un grupo solutrense representado por nueve puntas de cara plana y una hoja de laurel. Según V. Cabrera (1984) podría tratarse de un Solutrense Medio, quizá más evolucionado que el de Las Caldas, o bien en un momento inicial del Solutrense Superior.

En Cueva Morín, J. González-Echegaray y L. G. Freeman (1971) hallaron un nivel solutrense que reposaba directamente sobre el nivel IV 
encuadrado en el Gravatiense. El grupo solutrense de este único estrato está compuesto por 12 puntas de cara plana, 10 hojas de laurel, dos hojas de sauce y 19 puntas de muesca, de las que cuatro son de retoque abrupto. Los autores atribuyen este nivel a un Solutrense Superior, dada la existencia de puntas de muesca con un porcentaje relativamente alto de útiles sobre hojita.

Del Solutrense Superior son las figuras de ciervas con el interior finamente estriado presentes en las cuevas de El Castillo y Altamira y bien fechadas por figuras idénticas grabadas sobre hueso, halladas en sus yacimientos. También al Solutrense debe ser atribuida una parte de la decoración parietal de cueva Chufín y casi la totalidad de los grabados de El Queso (Llonín, Asturias).

En el área mediterránea este horizonte cultural habria que situarlo cronológicamente entre el $20.490 \pm 900 / 800$ B. P. (B.M. 859) del Parpalló (7,25-6,25 metros) encuadrado en un Solutrense Inferior (Davidson, I., 1974) y el $16.500 \pm 280$ B. P. del nivel II de la cueva de Ambrosio atribuido a un Solutrense Superior Evolucionado (Ripoll López, S., 1988). Además existen otras dataciones como la de $21.710 \pm 650 \mathrm{~B}$. P. (KN-l/) 920) del nivel VI de Les Mallaetes encuadrado en un Solutrense Inferior (Fortea, J., y Jordá, F., 1976) aunque parece un poco antigua, mientras que la de $13.200 \pm 600$ B. P. $(M-1019)$ de la cueva de Reclau Viver (Soler, N., 1986), posiblemente esté contaminada.

Cronoestratigráficamente habría que situar el Solutrense de la fachada mediterránea en un momento final del Würm IV, y gracias al análisis polínico de la cueva de Ambrosio se puede concretar la posición del nivel Solutrense Medio en el interestadio de Laugerie, con un clima templado y húmedo, y el Solutrense Superior y el Solutrense Superior y Evolucionado en el interestadio de Lascaux, más templado y ligeramente más seco. La fauna en casi todos los yacimientos mediterráneos está dominada por los lagomorfos (Oryctolagus cuniculus), asociados a restos de Capra pyrenaica, Cervus elaphus y Equus caballus. El paisaje sería muy similar al actual con una sucesión de bosques y praderas según la altura y el clima.

En el norte de la costa mediterránea, la zona catalana presenta unas caracteristicas industriales particulares, que vienen dadas por las técnicas de talla de retoque plano que presentan las puntas de muescas, así como por la ausencia de puntas de aletas y pendúnculo. Los yacimientos más importantes son El Reclau Viver (nivel entre 2,30 y 3 metros de profundidad) y L'Arbreda (niveles 13 a 16). El primero de ellos presenta dos momentos: un Protosolutrense, con puntas de cara plana poco defi- 
nido, y un Solutrense Superior, con piezas foliáceas (22,39 \%), que introducia las puntas de muesca de retoque plano (Corominas, M., 1960, y Soler, N., 1986). En la segunda estación el índice de foliáceos $(11,6 \%)$ varía sensiblemente y además las puntas de muesca son de retoque abrupto (Soler, N., 1986). Además de estos dos yacimientos también se han encontrado industrias solutrenses en Davant Pau, Cova d'en Pau, Cau d'en Paquito y Cau de les Goges, entre otros. Este último presenta un tipo de útil muy característico constituido por las hojas de laurel del subtipo F o asimétricas. Para N. Soler (1986) el Solutrense catalán presenta una originalidad que impide acomodarlo a la secuencia clásica.

Más el sur, en esta zona mediterránea se han citado muchas estaciones "solutrenses" entre las que algunas encajarian bien en esta definición, como la cueva de El Parpalló (Pericot, L., 1942), Les Mallaetes (Fortea, J., y Jordá, F., 1976) o Barranc Blanc (Fullola Pericot, J. M., 1979), mientras que otras, dada la escasez de restos, son de difícil atribución cultural.

En la parte meridional del área valenciana se encuentra el yacimiento de cueva Beneito en el que se ha identificado un nivel de Solutrense Superior Evolucionado que además cuenta con una datación de $16.560 \pm 480$ B. P. (Ly-3593) (Iturbe, G., 1986) muy similar a la obtenida para el mismo periodo en la cueva de Ambrosio.

A modo de puente entre la zona levantina y el área andaluza nos encontramos con la cueva de Ambrosio, yacimiento ya conocido desde antiguo (Ripoll Perelló, E., 1960/1961 y 1962) y cuyas recientes excavaciones (Ripoll López, S., 1986 y 1988) han permitido hallar una estratigrafía de 6,50 metros con tres niveles solutrenses. El nivel inferior (VI), atribuido al Solutrense Medio, cuenta con una datación de $16.590 \pm$ 1.400 B. P. (Gif. 7277) y con una serie industrial compuesta por puntas de cara plana y hojas de laurel y una escasa industria ósea. Para el segundo nivel (IV), encuadrable en el Solutrense Superior, contamos con una fecha de $16.620 \pm$ B. P. (Gif. 7275). El grupo solutrense está compuesto por algunas -escasas - puntas de cara plana, bastantes hojas de laurel y hacen su aparición las también escasas puntas de muesca y puntas de aletas y pedúnculo. En este momento empiezan a surgir los primeros útiles sobre hojita. El último nivel (II), situado en el Solutrense Superior Evolucionado, está datado en $16.500 \pm 280$ B. P. (Gif. 7276). El conjunto industrial solutrense está compuesto por hojas de laurei, no existen las puntas de cara plana, pero los tipos más característicos de este momento son las puntas de muesca de retoque abrupto y las puntas de aletas y pedúnculo. 
En toda la zona andaluza y en el Sureste peninsular se han atribuido numerosos yacimientos al Solutrense por la existencia de puntas de muesca como pueden ser la cueva de Los Ojos de Cozvijar (Toro, I., y Almohalla, M., 1985 y 1986) o la cueva del Pantano de Cubillas (Toro, I.; Almohalla, M., y Argamasilla, M., 1980) en la zona de Granada. En Murcia se citan la cueva de Palomarico y la de La Moneda, pero nosotros pensamos que la existencia de puntas de muesca de retoque abrupto si no aparecen asociadas con piezas que presenten retoque plano no pueden ser consideradas como solutrenses, ya que este tipo de útiles tienen una larga perduración cultural. Pero también existen yacimientos cuya atribución es más fiable como pueden ser la cueva del Tajo del Jorox (Marqués, I., y Ruiz, A., 1976), la de Nerja (Jordá Pardo, J., et alii, 1986), el Serrón, Cejo del Pantano y Mortolitos (Cacho, C., 1981; Ripoll López, S., 1988) que aunque presentan muy pocos útiles de retoque plano, lo que no permite una atribución cultural muy precisa, por lo menos se pueden incluir en un Solutrense sensu lato.

Respecto al arte recordaremos la importante colección de más de 5.000 plaquetas pintadas y/o grabadas de El Parpalló (Pericot, L., 1942). Es muy reciente, y aún no publicado en detalle, el hallazgo de grabados parietales en la Cova Fosca (Alicante) por M. Hernández. Además de formas geométricas cerradas, dicha cueva contiene algunas representaciones de ciervos que tienen exactos paralelos en las plaquetas de EI Parpalló. Además una parte al menos del arte paleolítico de Andalucía puede ser atribuido al Solutrense, como el de las cuevas de Navarro (Málaga), El Toro (Málaga), Morrón (Jaén) (López Payer, M. G., y Soria Lerma, M., 1983) y especialmente La Pileta (Málaga) (Ripoll Perelló, E., 1961/1962; Sanchidrián, J. L., 1982 y 1987).

Participando de las dos zonas descritas hallamos los yacimientos del área de Madrid. Los recientes estudios (Martínez de Merlo, A. M., 1984) que se están realizando sobre materiales procedentes de las excavaciones de Pérez de Barradas a principios de siglo han dado luz a la existencia de un Solutrense que siendo muy “clásico» introduce las puntas de aletas y pedúnculo aunque no se han encontrado puntas de muesca. Algo similar ocurre con las series que se están estudiando en la zona de Portugal (Zilhao, J., 1984) en los que aparecen los mismos tipos de útiles.

Recientemente se ha encontrado la cueva de Chaves (Huesca) en la que los excavadores citan un conjunto de 13 puntas de muesca de retoque abrupto $\sin$ estar asociadas a útiles de retoque plano, con una datación de $19.700 \pm 310$ B. P., que encuadran dentro de un "Solutrense Superior Cantábrico» (Baldellou, V., y Utrilla, P., 1984). 
Queda evidente que la mayor parte del conocimiento que tenemos de los periodos Gravetiense y Solutrense en la Península Ibérica se refiere sobre todo al área cantábrica y a la fachada mediterránea, incluida Andalucia. Es de esperar que las investigaciones que se están realizando colmen en un futuro inmediato el espacio vacio que representa el no contar con secuencias cronoestratigráficas recientes en las zonas antes mencionadas y en absoluto para el área central. 


\section{BIBLIOGRAFÍA}

Alcalde del Río, H., 1906: Las pinturas y grabados de las cavernas prehistóricas de Santander.

APARICIO, J., 1977: “Investigaciones arqueológicas en Gandia y la Safor», Gandia (Gandia), 1977, págs. 69-76.

BALdellou, V., 1987: “Arte rupestre en la región pirenaica", en Arte rupestre en España, Madrid, págs. 66-77.

Baldellou, V., y Utrilla, P., 1985: "Nuevas dataciones de radiocarbono de la prehistoria oscense", Trabajos de Prehistoria (Madrid), vol. 42 , 1985, págs. 83-95.

BaRANDIARÁN, I., 1980: “Auriñaciense y Perigordiense en el País Vasco: Estado actual», Munibe, San Sebastián, año XXXII, núm. 3-4, págs. 325-333.

BeRnaldo DE Quirós, F., 1977: «El Paleolítico Superior inicial en la Región Cantábrica Española", XIV Congreso Nacional de Arqueología, Vitoria, 1975, Zaragoza, págs. 151-156.

- 1981: “L'Aurignacién et le Perigordién sur la façade atlantique de l'Espagne", $X$ Congreso de la U.I.S.P.P., México, 1981, págs. 23-26.

- 1982: "Los inicios del Paleolítico Superior Cantábrico", Centro de Investigación y Museo de Altamira, Monografias, núm. 8, Madrid, 347 páginas.

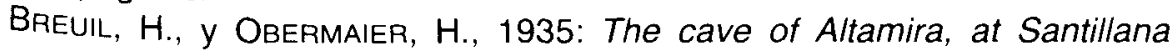
del Mar, Spain. Junta de las cuevas de Altamira y The Hispanic Society of America y la Academia de la Historia. Madrid, 1935.

BUTZER, K. W., 1980: "Investigación preliminar de la geología de la cueva del Pendo». En J. González Echegaray et alii, «El yacimiento de la cueva del Pendo, Bibliotheca Praehistorica Hispana, Madrid, 1980, vol. XVII, págs. 199-214. 
Cabrera, V., 1977: “El yacimiento solutrense de cueva Chufín (Riclones, Santander), XIV Congreso Nacional de Arqueologia, Vitoria, 1975, Zaragoza, 1977, págs. 157-164.

- 1984: «El yacimiento de la cueva del Castillo (Puente Viesgo, Santander)", Bibliotheca Praehistorica Hispana, vol. XXII, C.S.I.C. Madrid, 1984, 485 páginas.

Cacho, C., 1981: El Paleotítico Superior en el Sureste de la Península Ibérica. Tesis doctoral. Universidad Complutense de Madrid, 689 páginas.

CorChón, M. S., 1981: "La cueva de Las Caldas, San Juan de Priorio (Oviedo)". Excavaciones Arqueológicas en España, núm. 115, Madrid, 1981, 268 págs.

Corominas, M., 1960: El Solutrense del Reclau Viver de Serinyá. Tesis de la Licenciatura en la sección de Historia de la Facultad de Filosofía y Letras, Barcelona 1960. Original inédito.

DavidSON, I., 1974: "Radiocarbon dates for the Spanish Solutrean", Antiquity, vol. 48, Londres, 1974, págs. 63-65.

ForTEA PEREZ, J., 1978: “Arte paleolítico del Mediterráneo español», Trabajos de Prehistoria, t. 35, 1978, págs. 99-149, 35 figuras.

FORTEA, J., et alii, 1983: "Schéma paléoclimatique, faunique et chronostratigraphique des industries à bord abattu de la région méditerranéenne espagnole", Rivista di Scienze Preistoriche, vol. XXXVIII, Siena, págs. 21-67.

ForTEA, J., y JORDA, J., 1976: "La cueva de Les Mallaetes y los problemas del Paleolítico Superior del Mediterráneo español», Zephyrus, t. XXVI-XXVII, Salamanca, 1976, págs. 127-166.

Fullola Pericot, J. M., 1979: "Las industrias líticas del Paleolítico Superior Ibérico", S.I.P., Trabajos Varios, núm. 60, 1979, 262 páginas.

Gonzalez Echegaray, J., y Freeman, L. G., 1971: Cueva Morín. Excavaciones 1966-1968. Publicaciones del Patronato de las Cuevas Prehistóricas de la provincia de Santander. Santander, 1971, 452 páginas.

HoYOS, M., y LAVILLE, H., 1982: “Nuevas aportaciones sobre la estratigrafia y sedimentología de los depósitos del Paleolítico Superior de la cueva del Pendo (Santander): sus implicaciones", Zephyrus, Salamanca, 1982, págs. 285-293.

ITURBe POlo, G., 1986: "Cova Beneito", en Arqueología en Alicante, 1976-1986. Instituto de Estudios “Juan Gil Albert», Diputación Provincial de Alicante, págs. 71-73.

JordA CERdA, F., 1955: El Solutrense en España y sus problemas. Servicio de Investigación Arqueológica de la Diputación Provincial de Asturias, Oviedo, 1955, 200 páginas. 
JoRdA PARDo, J. F. (Edit.), 1986: Trabajos sobre la Cueva de Nerja, número 1, La Prehistoria de la Cueva de Nerja (Málaga). Patronato de la Cueva de Nerja, Málaga.

LAVILLE, H., 1980: "Les dépots solutréens de la grotte de La Riera (Asturias). Signification climatique et chronologique", B.S.P.F., vol. 8, C.R.S.M., págs. 234-236.

LEROI-GOURHAN, Arl., 1959: «Résultats de l'analyse pollinique de la grotte d'Isturitz", B.S.P.F., vol. 56, págs. 619-624.

LOPez PAYer, M. G., y Soria LeRma, M., 1983: "Las pinturas rupestres paleolíticas de la cueva de «El Morrón» (Torres, Jaén)», Ars Praehistorica, vol. II, págs. 195-206.

MARqués, I., y Ruiz, A., 1976: “El solutrense de la cueva del Tajo de Jorox, Alozaina (Málaga)", Cuadernos de Prehistoria de la Universidad de Granada, núm. 1, 1976, págs. 47-57, 6 figuras y III láminas.

Martínez de Merlo, A. M., 1984: “El Paleotítico Superior del Valle del Manzanares: El yacimiento del Sotillo", Boletín del Museo Arqueológico Nacional, vol. II, 1984, págs. 47-68.

MiRalles Viciano, J. L., 1982: «El Gravetiense en el Pais Valenciano», Saguntum, vol. 17, Valencia, 1982, págs. 45-63.

Pericot, L., 1942: La cueva de El Parpalló (Gandía). Excavaciones del Servicio de Investigación Prehistórica de la Diputación de Valencia. C.S.I.C., Instituto Diego Velázquez, Madrid, 1942, 351 páginas.

RIPOLL LOPEZ, S., 1984: El Solutrense de Cueva de Ambrosio (VélezBlanco, Almería): Campaña de 1963. Memoria de Licenciatura, Universidad de León 1984, 425 páginas.

- 1986: «El Solutrense de Cueva de Ambrosio (Vélez-Blanco, Almería) Campaña de 1963", E.A.E. núm. 168, 1986, 330 páginas, 40 figuras y 30 láminas.

- 1987: La Cueva de Ambrosio (Vélez-Blanco, Almería) y su posición cronoestratigráfica en el Mediterráneo occidental. British Archaeological Report, International Series, n. ${ }^{\circ}$ 462, Oxford, 1988, 596 págs., 116 figuras y LV láminas.

Ripoll Perello, E., 1960, 1961: “Excavaciones en cueva de Ambrosio (Vélez-Blanco, Almeria), Campañas de 1958-1960", Ampurias, t. 2223, Barcelona, 1960-1961, págs. 31-44.

- 1961, 1962: "La cronología relativa del santuario de la cueva de La Pileta y el Arte Solutrense", Homenaje al Profesor Cayetano de Mergelina, Murcia, 1961-1962, págs. 1-13.

- 1962: “Excavaciones en cueva de Ambrosio (Vélez-Blanco, Almeria), VII Congreso Arqueológico Nacional, Barcelona 1961, Zaragoza, 1962, págs. 117-121, II láminas. 
Saint- Perier, R. y S., 1952: "La Grotte d'Isturitz, III, les Solutréens, les Aurignaciennes, et les Mousteriens", Mémoires de I'I.P.H. núm. 25 , París, 1952.

SANCHIDRIÁN TORTI, J. L., 1982: "La cueva del Morrón (Jimena, Jaén)", Zephyrus, vol.X XXIV-XXXV, Salamanca, págs. 6-16.

- 1987: "Arte rupestre en Andalucia", Arte Rupestre en España, Madrid, págs. 96-105.

SOler MASFERRER, N., 1986: Les industries del Paleolitic Superior en el Nord de Catalunya. Tesis Doctoral leída en la Universidad Central de Barcelona. Inédita.

Strauss, L. G., 1983: «El Solutrense Vasco-Cantábrico. Una nueva perspectiva", Centro de Investigación y Museo de Altamira, Monografias, núm. 10. Madrid, 1983, 175 páginas.

Strauss, L. G., et alii, 1986: La Riera Cave Stone Age Hunter-Gatherer Adaptations in Northern spain, 1986.

ToRo, I., y ALmOHALLA, M., 1979: "Industrias del Paleolítico Superior en la provincia de Granada", Cuadernos de Prehistoria de la Universidad de Granada, núm. 3, Granada, 1979, págs. 1-20.

- 1985a: "Le gisement de la Cueva de los Ojos (Cozvijar, Granada)", B.S.P.F., núm. 82, 4, 1985, págs. 116-119, 3 figuras.

- 1985b: «Descubrimiento de industria del Paleolítico Superior en la provincia de Granada. El yacimiento soluntrense de la "Cueva de los Ojos (Cozvijar, Granada)», XVII Congreso Nacional de Arqueología, Logroño 1983, Zaragoza, 1985, págs. 97-104.

Toro, I.; Almohalla, M., y Argamasilla, M., 1980: "Nuevas aportaciones al conocimiento de las industrias del Paleolítico Superior en la provincia de Granada», Cuadernos de Prehistoria de la Universidad de Granada, núm. 5, Granada, 1980, págs. 1-13.

VeGa Del Sella, Conde de, 1916: "El Paleolítico de Cueto de la Mina (Asturias)", C.I.P.P., vol. 4, Madrid, 1916.

VILlaVerde, V., 1979: “El Solutrense en el País Valenciano. Estado actual de su conocimiento", Saguntum, núm 14, Valencia, 1979. págs. 9-31.

ZILHAO, J., 1984: "O Solutrense Superior de facies cantabrico de Vale Almoinha (Cambelas, Torres Vedras)", O Arqueologo Portugues" (Porto), vol. IV, núm. 2, 1984, págs. 15-86. 